\title{
AL-KITAB AT TA’LIMIY LIMADDATI AL-LUGHAH AL-ARABIYYAH ALA ASAASI NAZHARIYATI WAHDATI LI THOLABATI AL-MA'HAD AL-HIKAM MALANG
}

\author{
الكتاب التعليمي لمادّة اللغة العر بية على أساس نظرية الوحدة \\ لطلبة المعهد الحكم مالانج (ALL IN ONE SYSTEM) \\ Moh.Nadhif \\ STAIMA Ma’had Aly al-Hikam Malang \\ buya.nadhif@gmail.com
}

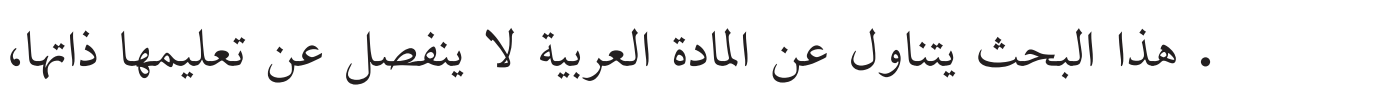
وارتفعت شكوى المتعلمين من صعوبته وتعقده. وهذا كله يدفع إلى اللغة العربية

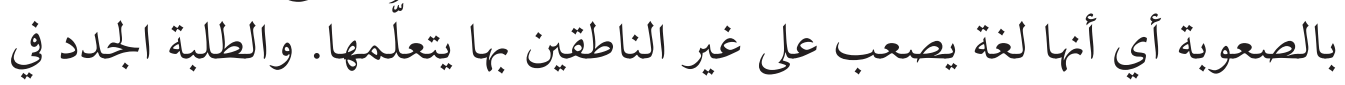

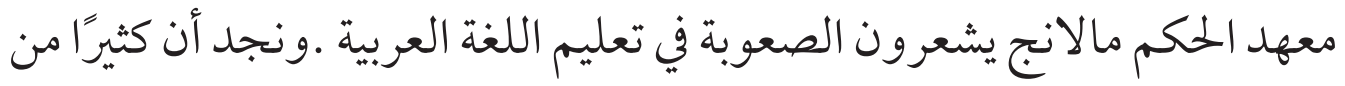

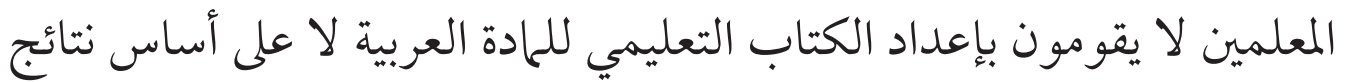

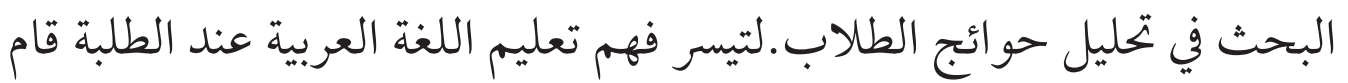

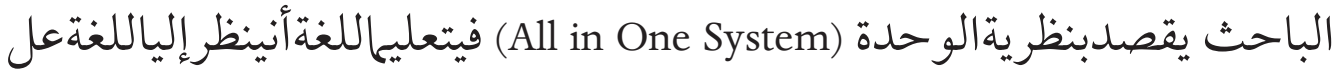

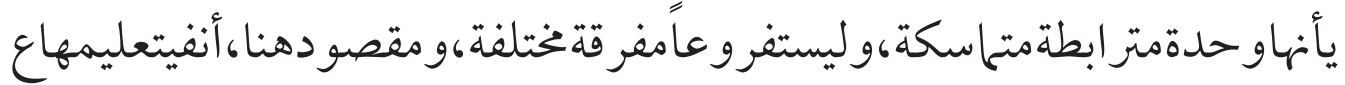

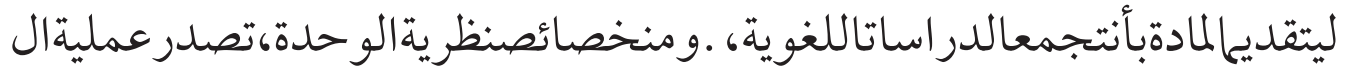

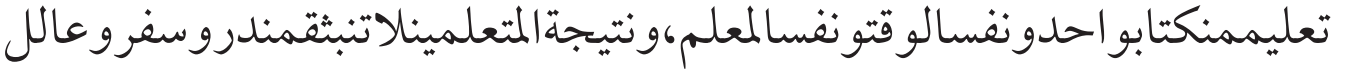

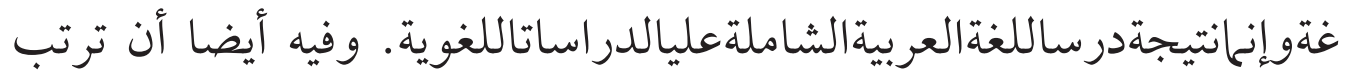
مو اد اللغة العربيى ـ اعتمادا على الملاحظات فيلايل سبق، ترى الباحثة أهمية تنمية الكتاب التعليمي في مادة الللغة العربية في معهد الحكم مالانج.

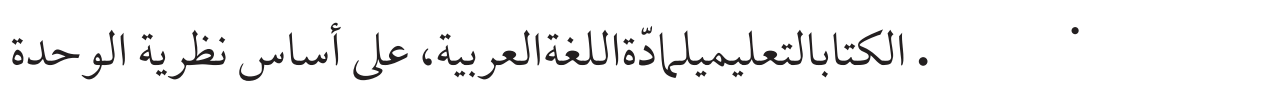




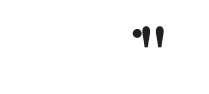

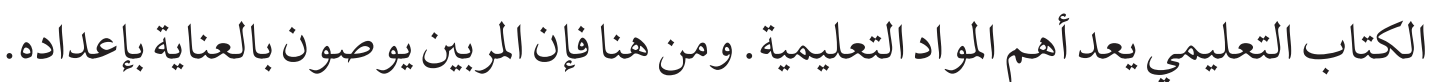

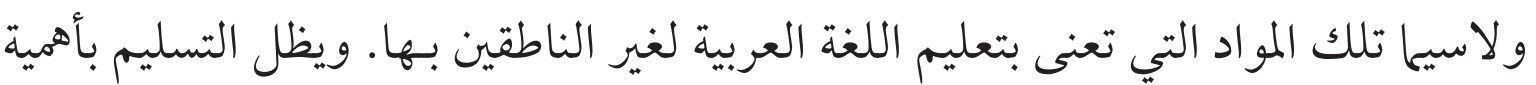

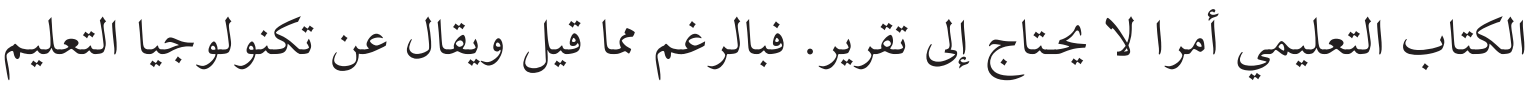

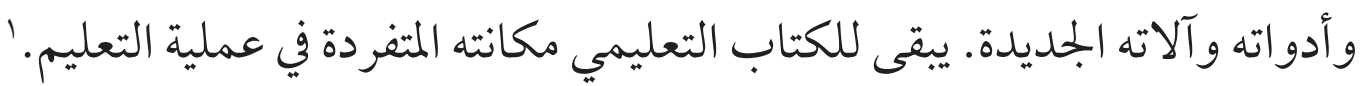

فعملية التعليم أيا كان نوعها أو نمطها أو مادتها ومحتويها تعتمد اعتمادا كبيرا على الكتاب التعليمي. فهو يمثل بالنسبة للمتعلم أساسا باقيا لعملية تعلم منظمة. وأساسا

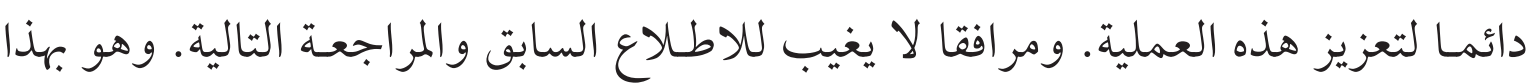

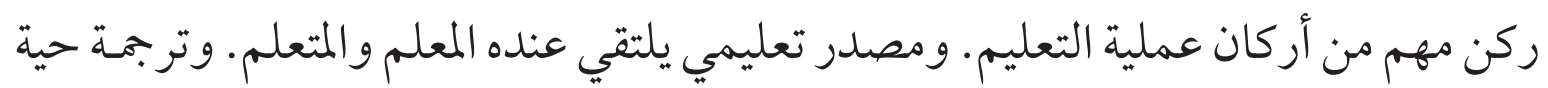

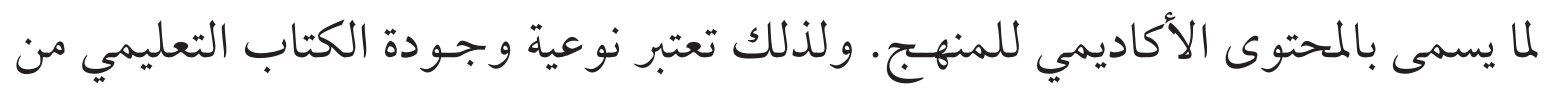

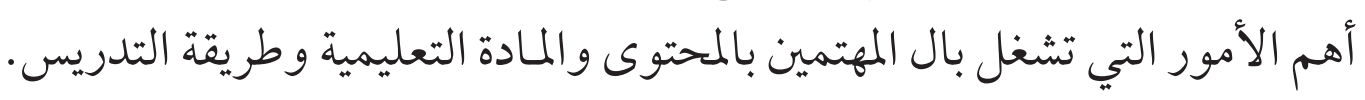

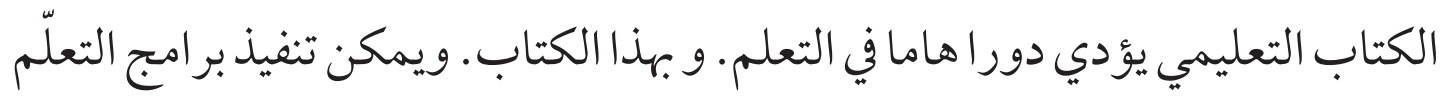

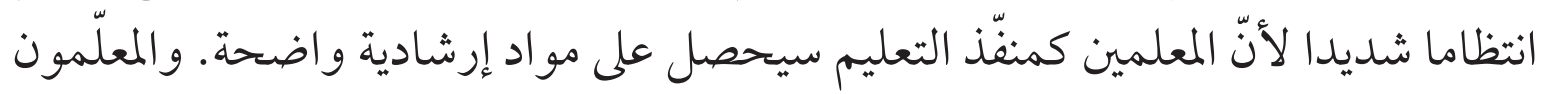

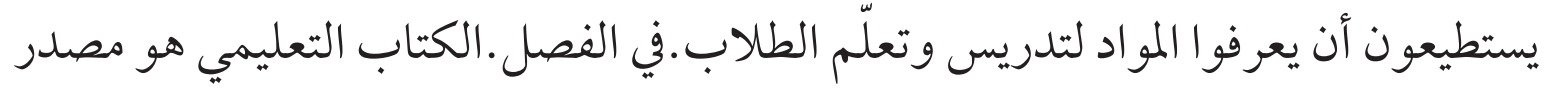

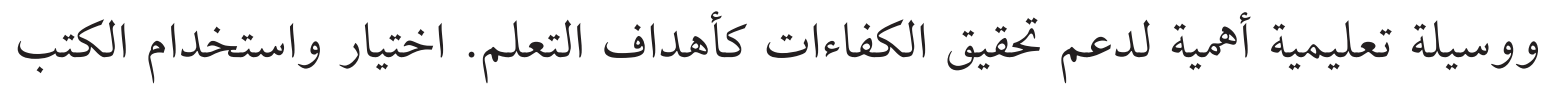
المدرسية كمصدر ووسائل تعليمية مناسبة هي عامل دعم النجاح في التعلم.

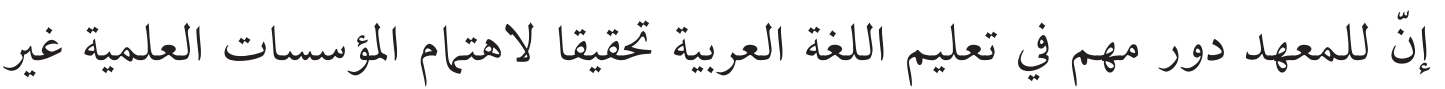

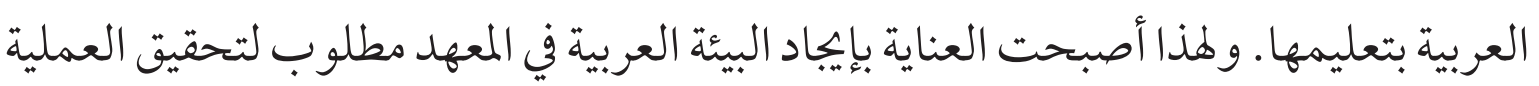

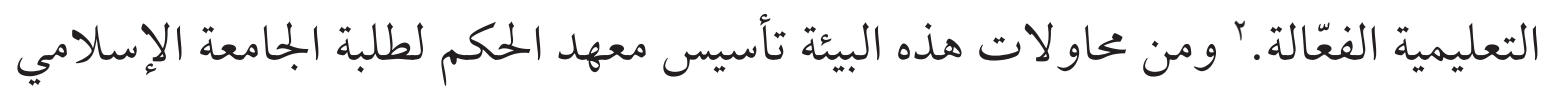
الذي أسّس في بيئة هذا المعهد.

فهذا المعهد يسعى إلى أن ييعل طلبته مؤهّلين باللغة العربية بجانب تأهيلهم باللغة

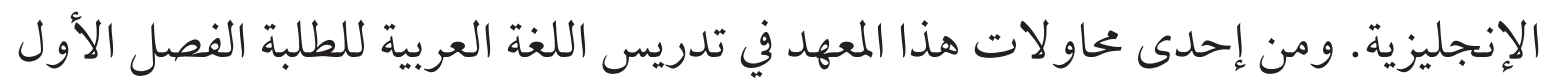

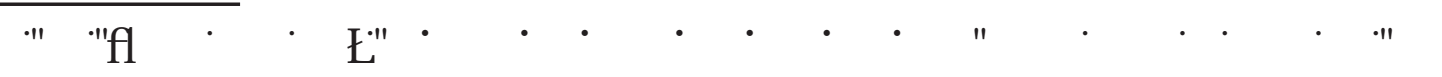

2 D.Hidayat. Pelajaran Bahasa Arab untuk Madrasah Aliyah kelas X. (Semarang. Toha Putra.2008) hal. 
الجدد من معهد الحكم لطلبة الجامعة الإسلامي في الكفاءة الغوية الأساسية. إن الكتاب المعدّ في هذه المرحلة فقط على قوائم المفردات والكلام دون غيرها من

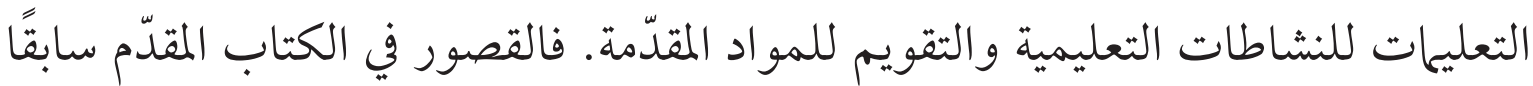

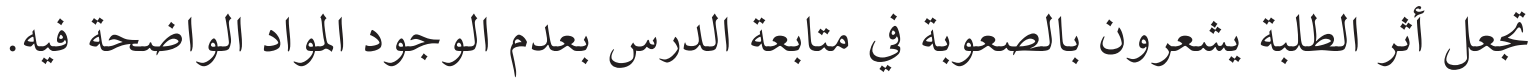

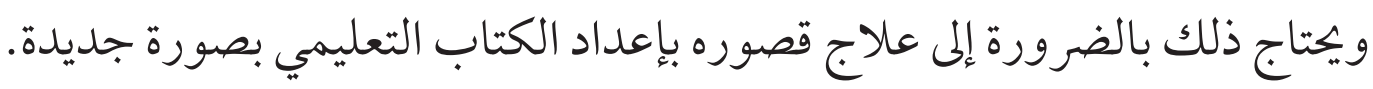

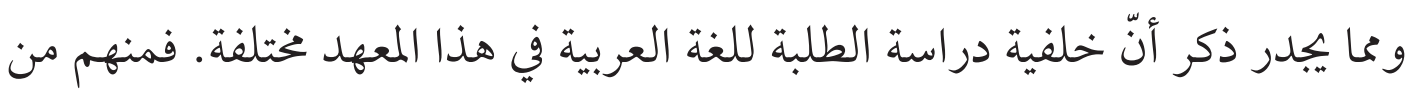

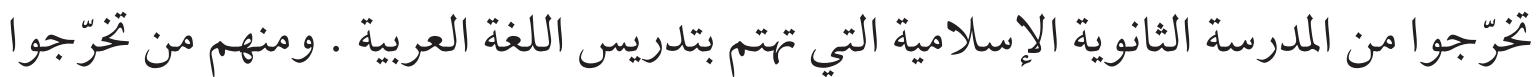

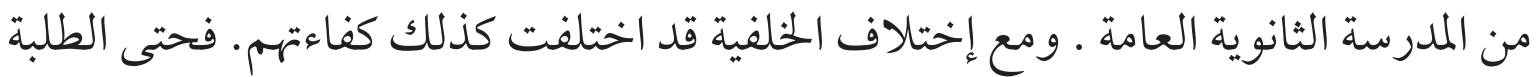

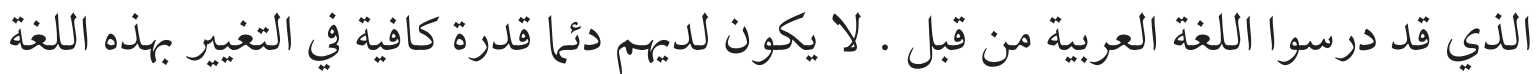

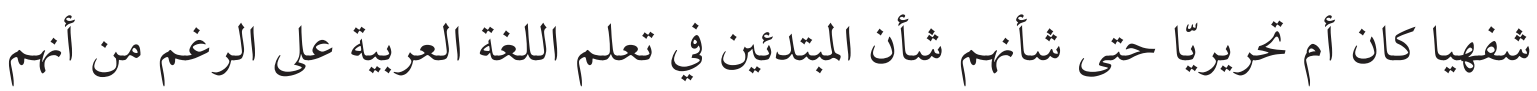

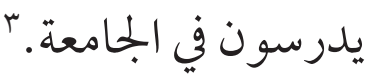

فالعملية التعليمية بالأسلوب المذكور سابقا قد يصح مملأ لهؤلاء الطلبة ذي إختلاف

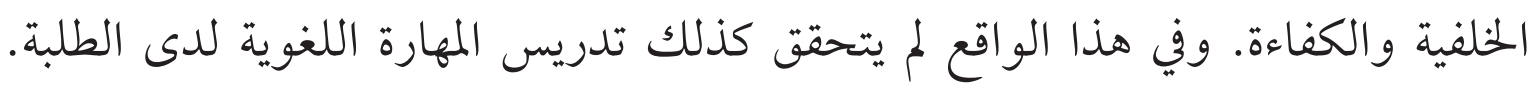

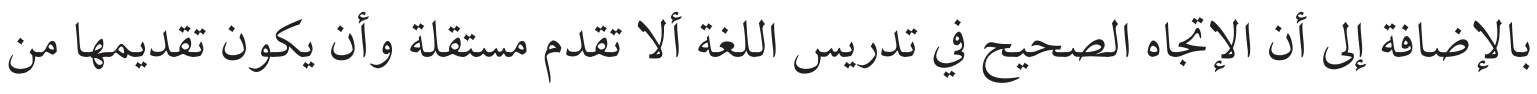
خلال تدريس الإستحاع والكلام والقراءة والكتابة.

فالإتجاه في التربية الحديثة يرمي إلى تدريس المهارة. وتعليم اللغة على أنها حقائق عملية

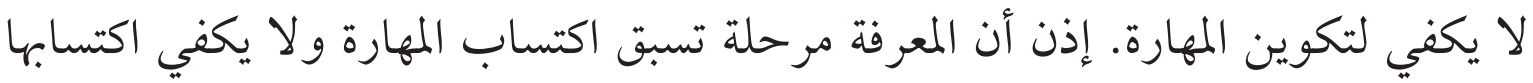

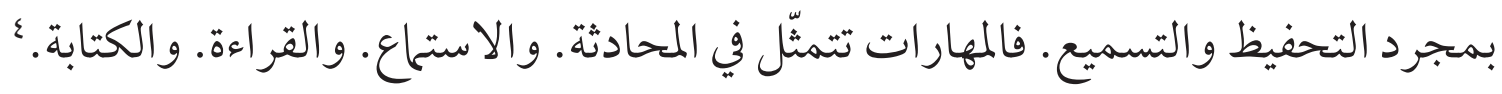
ومن هذا المنطلق رأى الباحث أهمية تقديم المهارات اللغوية الأربعة والقو اعد في دورة

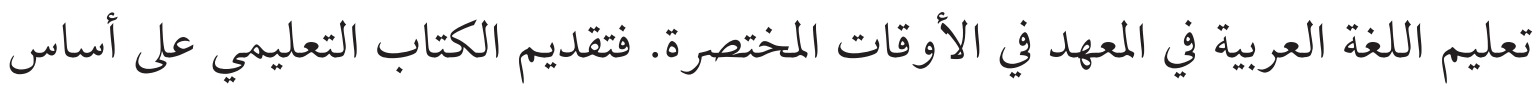

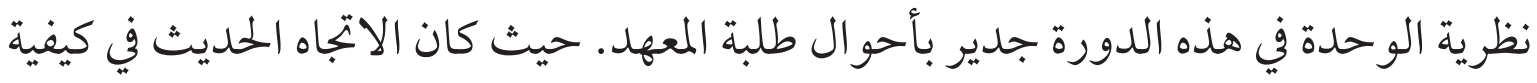

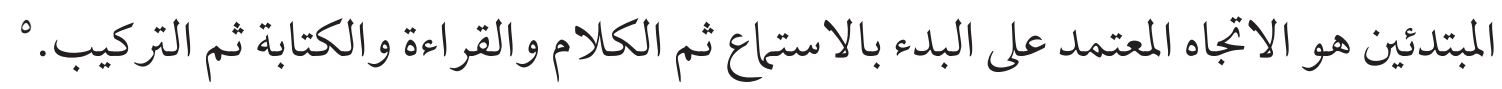

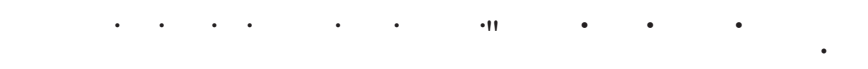

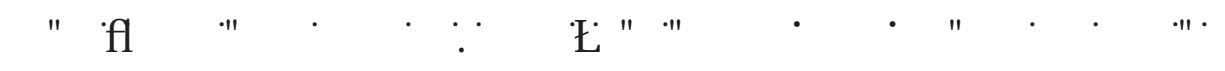

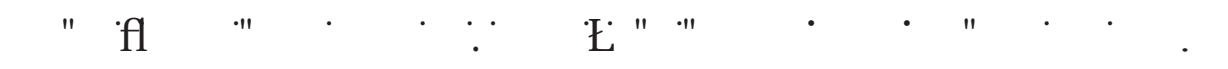


من خلال ذلك العرض السابق ودّ الباحث إعداد الكتاب التعليمي لتدريس اللغة

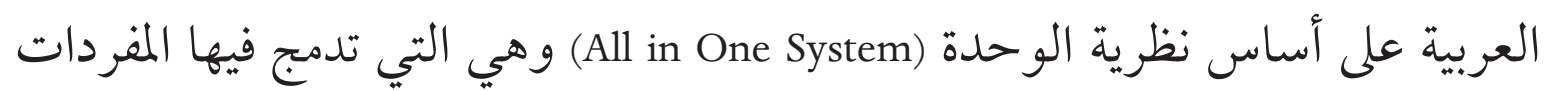

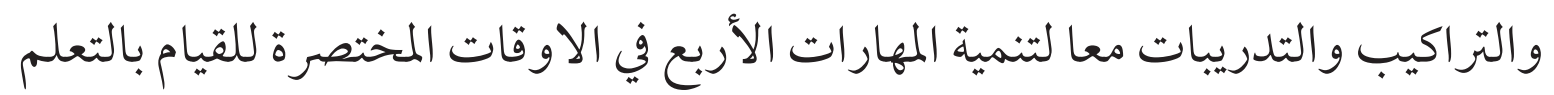

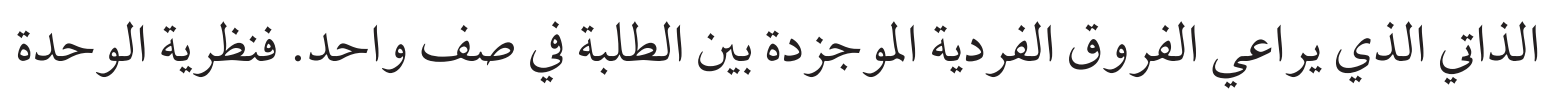

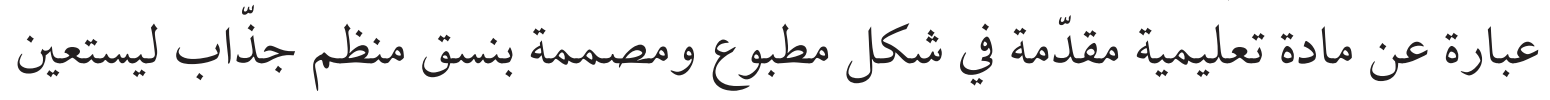

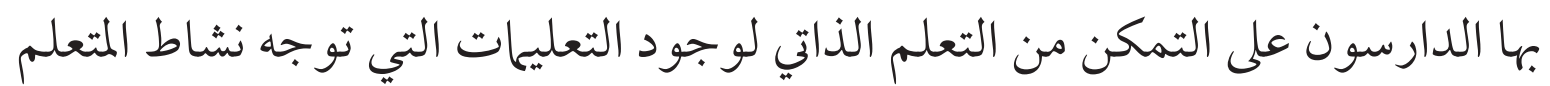

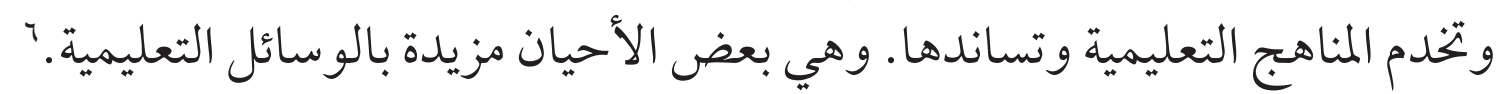
وإعداد الكتاب التعليمي في هذه الصورة يناسب الفلسفة التربوية بأن هناك الكاك

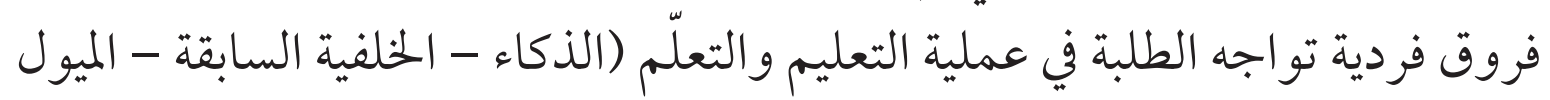

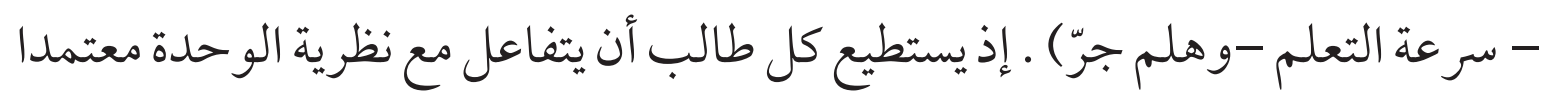

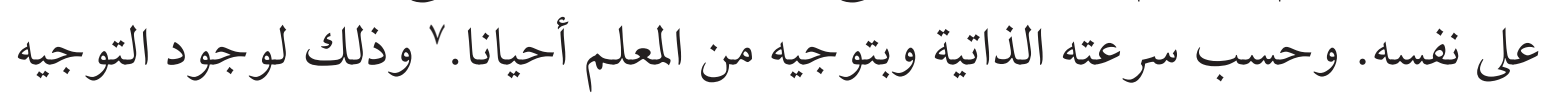

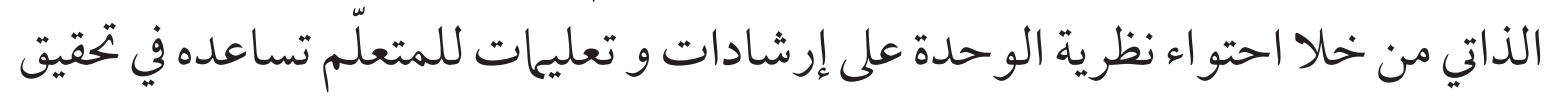
أهدافه.

فكل ما سبق ذكره دفع الباحث للقيام بإجر اء البحث بعنو ان (إعداد الكتاب

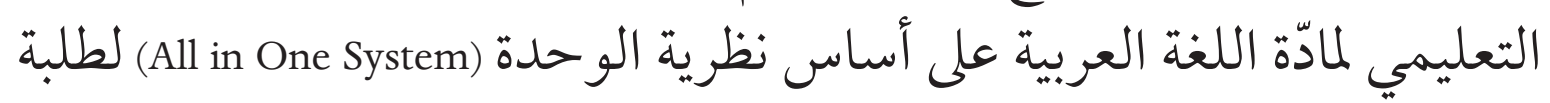

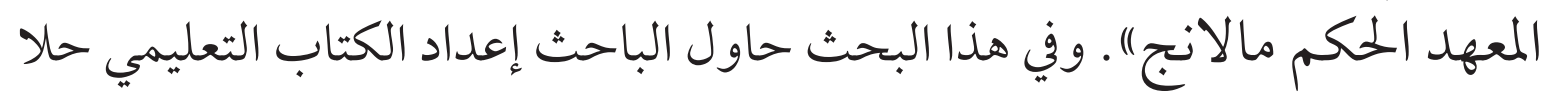

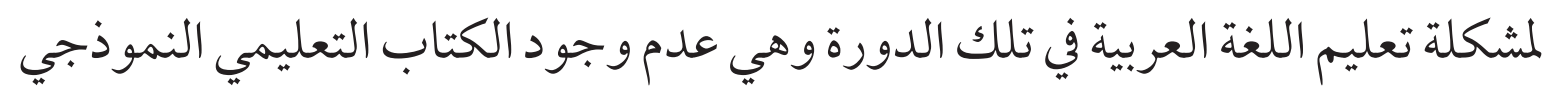

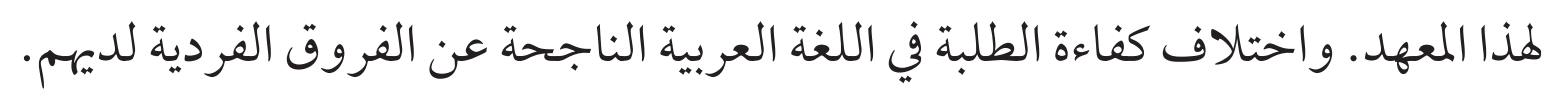
وكذالك نتيجة عن اختلاف خلفية دراستهم في تعلم اللغة العربية.

6. Direktorat Tenaga Kependidikan. Direktorat Jenderal Pendidikan Mutu Pendidikan dan Ketenaga Kependidikan. Departemen Pendidikan Nasional. Penulisan Modul. (Jakarta:2008) hal:3

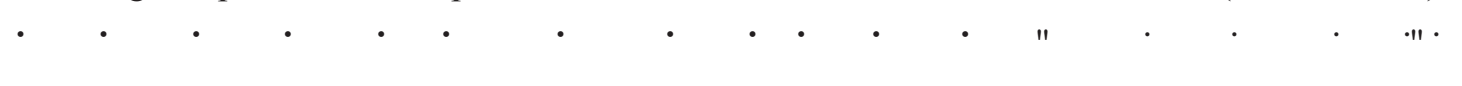

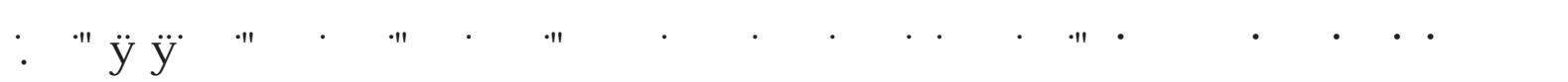

æế

血 势解

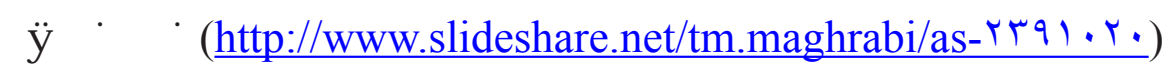




\section{Td\&}

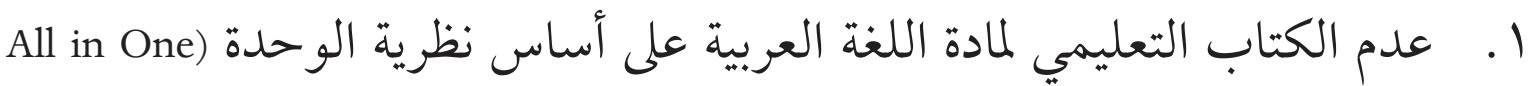

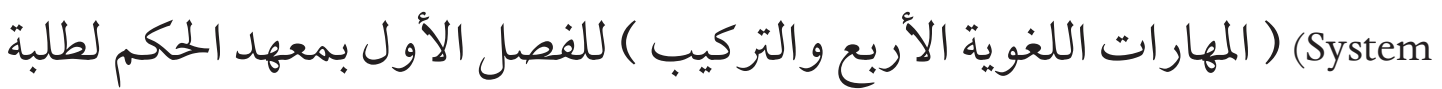
الجامعة الإسلامي مالانج r. .يصعب على كثير من الطلبة في متابعة درس اللغة العربية

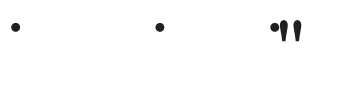

اعتمادا على الخلفية السابقة. تثثلت مشكلة البحث في محاولتها أن يقدم الباحث

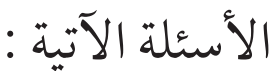

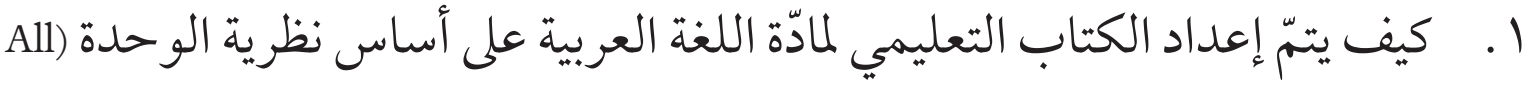
(in One System لطلبة المعهد الحكمم مالانج

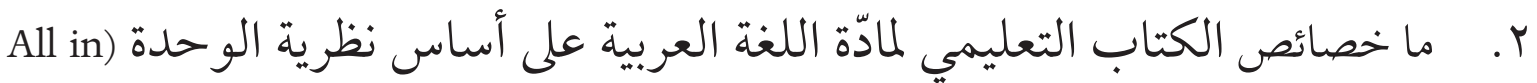

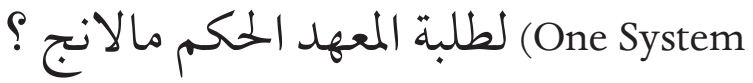

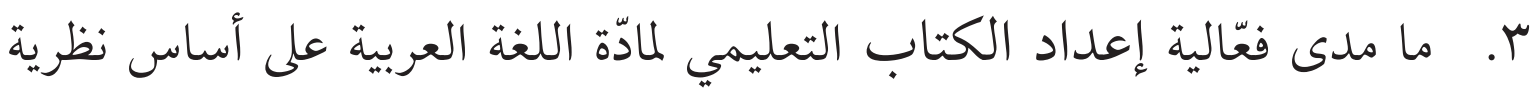

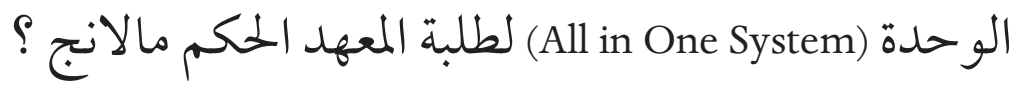

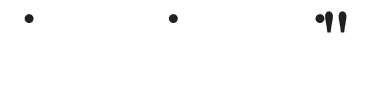

إعتمادا على أسئلة البحث السابقة. يهدف هذا البحث الوصول إلى الأهداف الآتية :

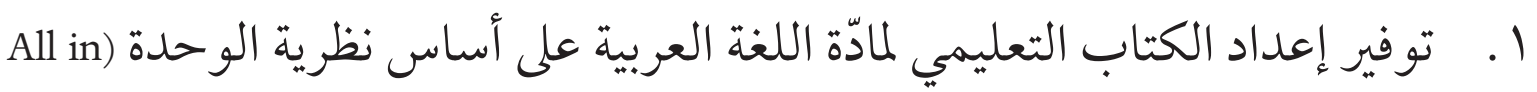

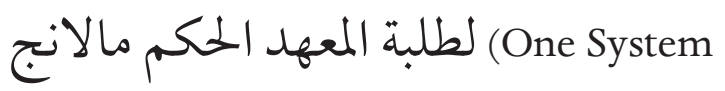
r. لوصف خصائص الكتاب التعليمي لمادّة اللغة العربية على أساس نظرية الوحدة

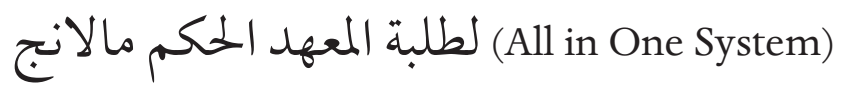
r. معرفة مدى فعّالية إعداد الكتاب التعليمي لمادّة اللغة العربيةعلى أساس نظرية

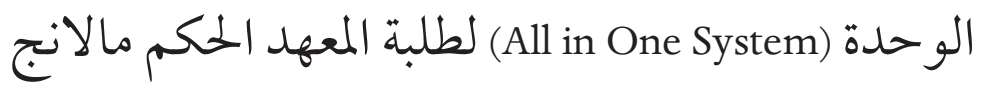




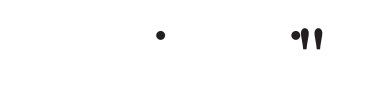

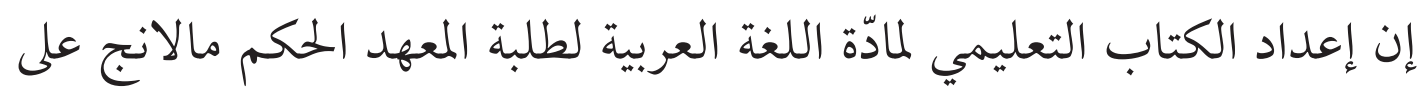
أساس نظرية الوحدة (All in One System) لترقية كفاءة الطلبة في المهارات اللغوية المعاد العية الأربع

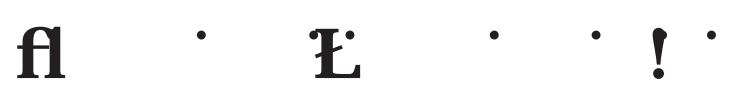 تتضح أهمية البحث الذي قام به الباحث فيا يلي :

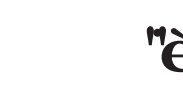

تأتي أهمية هذا البحث كونه إسهاما في تقنيات التعليم لتحديث طرق التدريس

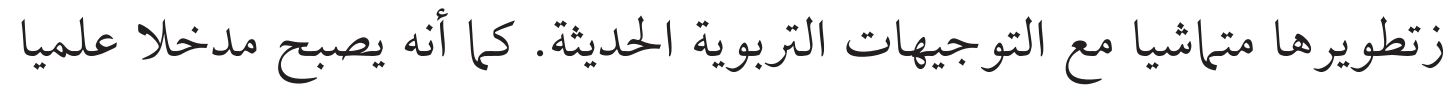

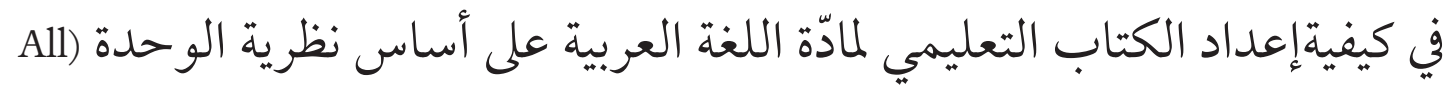

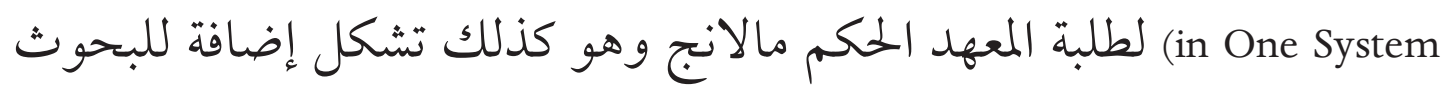
الموجودة عن إعداد المادة التعليمية.

\section{这估}

أ. للباحث : إن إعداد الكتاب التعليمي سيكسب الباحث خبرة مفيدة في إعداد

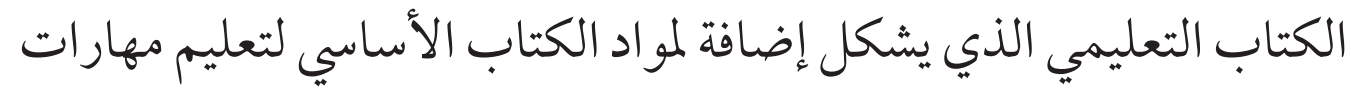

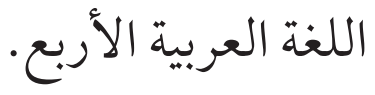

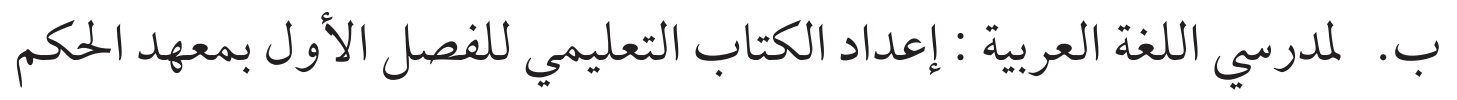

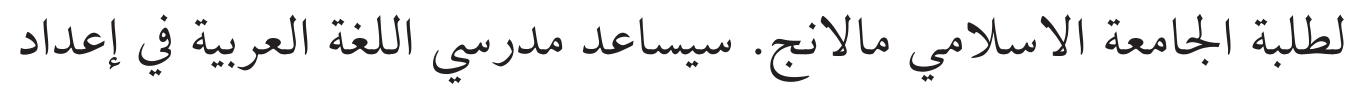

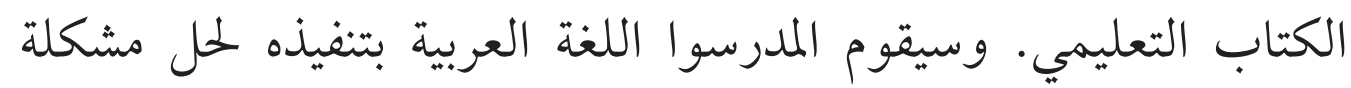

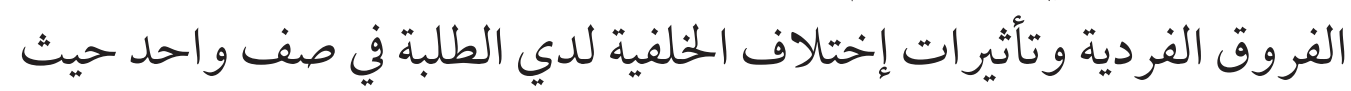

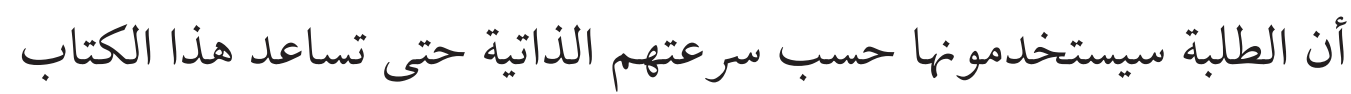

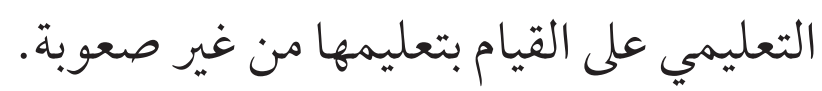


ج. للطلبة : سيستخدم الطلبة المبتدئون بمعهد الحكم لطلبة الجامعة الاسلامي

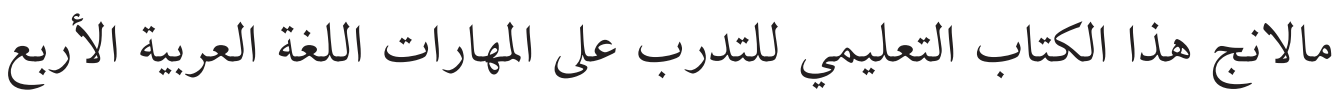

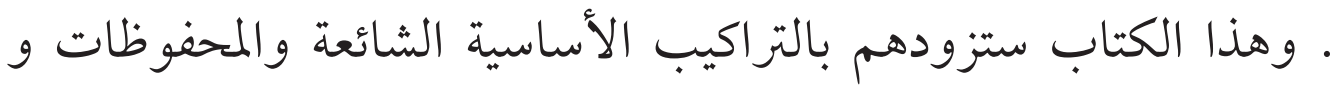

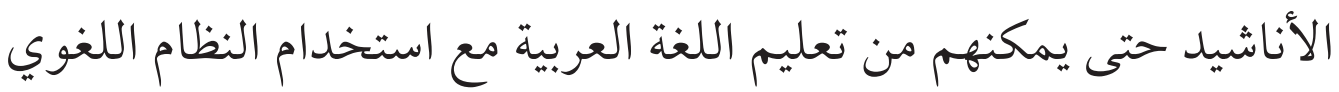
بطافية وبصورة لائقة. بالإضافة إلى أن نظرية الوحدة (All in One System)

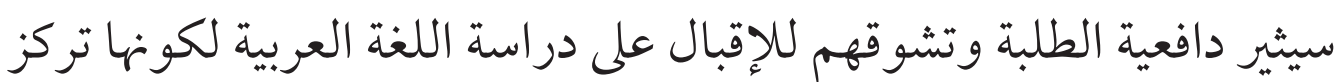
على المتعلم بإعتبار محور العملية التعليمية.

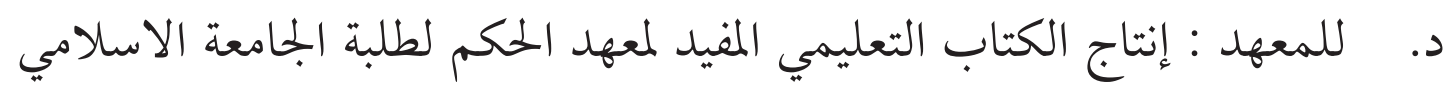

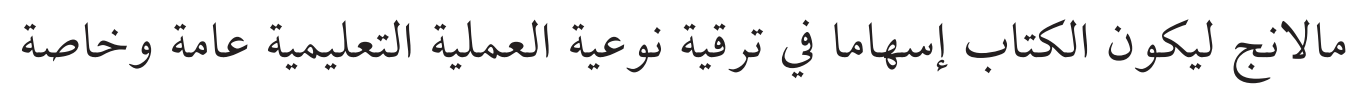

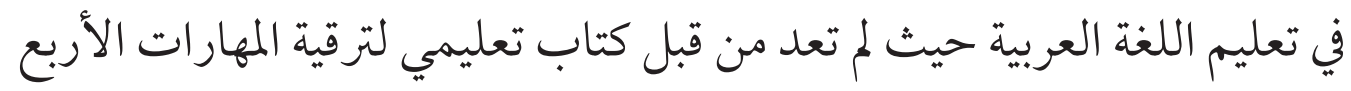
لم لدور تعليم اللغة العربية بهذا المعهد.

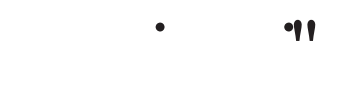

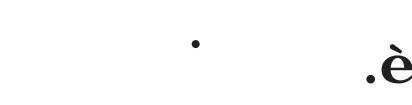

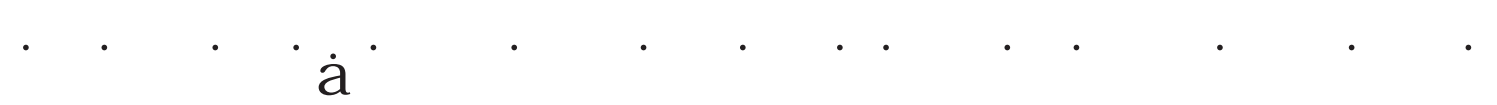

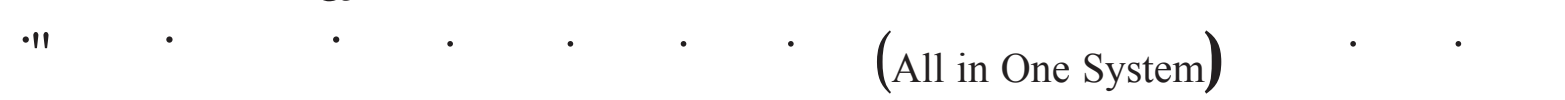

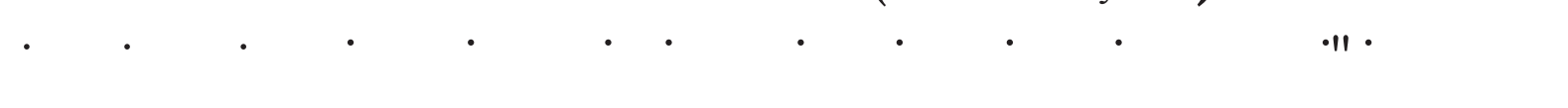

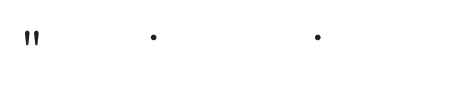

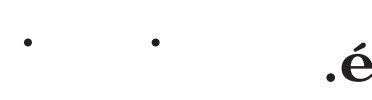

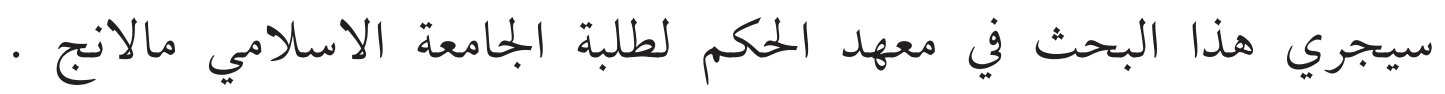

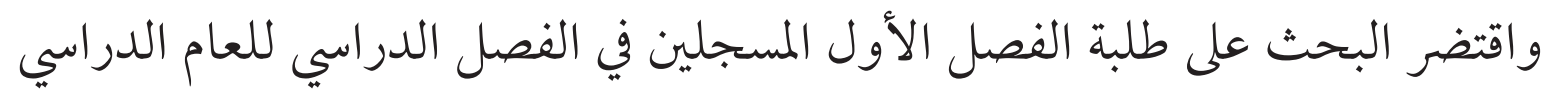
$. r \cdot 10 / r \cdot 1 \varepsilon$

\section{๑}

تم إجراء هذا البحث في الفصل الدراسي الثاني من العام الدراسي ع • r/ 10 ب من 
شهر مارس سنة 10 ب حتى أغسطس سنة 10 • r ( وتمّ التطبيق المادة التعليمية في خلال

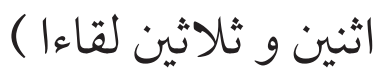

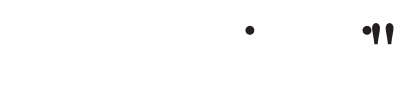

استخدم الباحث بعض المصطلحات المهمة في هذا البحث. ولتسهيل فهمها شرح

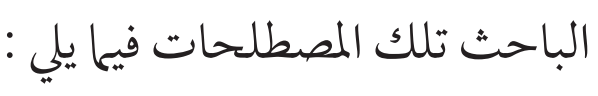

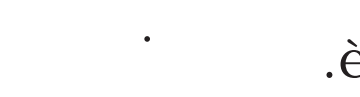

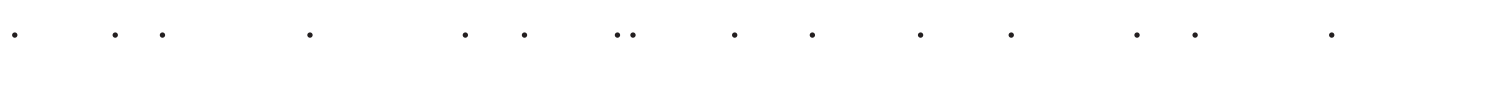

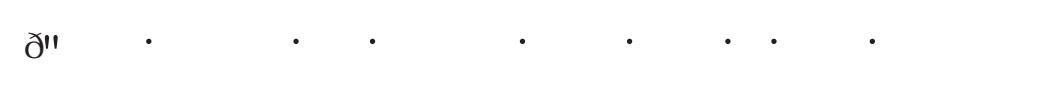

والمر اد بالكتاب التعليمي في هذا البحث هو الكتاب التعليمي المصنوع المناسب الذي

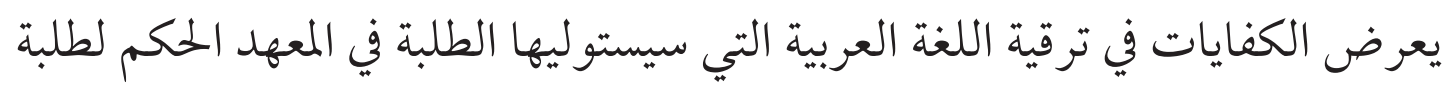
الجامعة مالانج ومستخدمة في عملية التعليم للحصول على الأهداف المعينة.

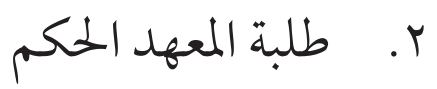

المراد الباحث ـ هو الطلاب الجدد لصف الأول بمعهد الحكم لطلبة الجلامعة الإسلامي مالانج جاوى الشرقية إندونيسيا. r. م. نظرية الوحدة (All in One System) يقصد بنظرية الوحدة (All in One System) في تعليم اللغة أن ينظر إلى اللغة على

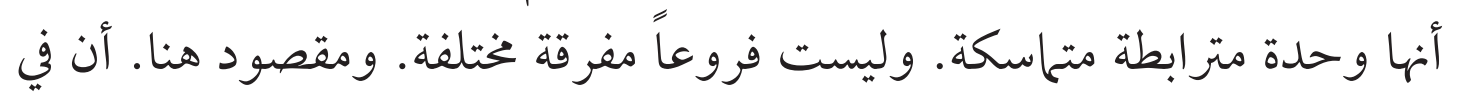
تعليمها على تقديم المادة بأن تجمع الدراسات متركات اللغوية. ومن خصائص نظرية الوحدة. تصدر عملية التعليم من كتاب واحد و نفس الوقت ونفس المعلم. ونتيجة المتعلمين لاتنبثق من دروس فروع اللغة وإنها نتيجة درس اللغة لته

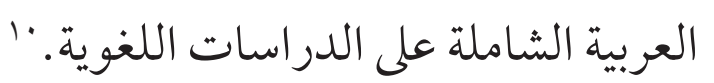

9 AndiPrastowo.PanduanKreatifMembuatBahanAjarInovatif(Yogyakarta: DIVAPress. 2012). hlm. 168.

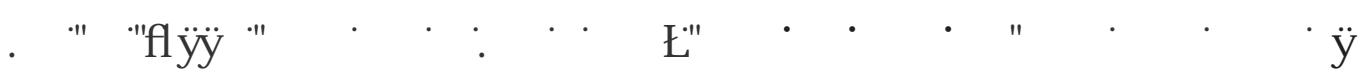


مغهوم نظرية الوحدة (All In One System) نظرية الوحدة فى تعليم اللغة هي "أن ننظر إلى اللغة على أنها وحدة مترابطة

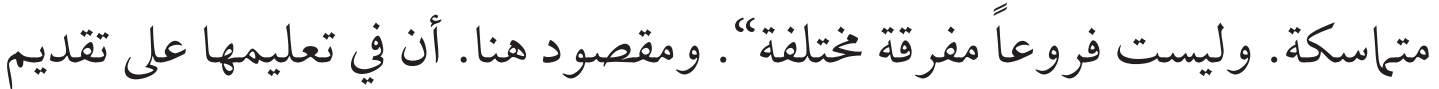
الملادة بأن تجمع الدراسات اللغوية.

ومن خصائص نظرية الوحدة. تصدر عملية التعليم من كتاب واحد و نفس الوقت ونفس المعلم. ونتيدة المتعلمين لاتنثق من دروس فروع اللغة وإنحا نتيجة درس اللغة العربية الشاملة على الدراسات اللغوية. أما لتطبيت نظرية الوحدة في تعليم اللغة يتخذ الموضوع أو النص حور اًتدور حوله هميع الدراسات اللغوية. فيكون هو موضوع القراءة. و التعبير . والتذوق. والحفظ و الإملاء. و التدريب اللغوى. فموضوع ”المكتبة المدرسية“" تبدأ بالمفردات ثمّ الحوار والبيان عن القواعد ويتراوح التدريبان حول هذا الموضوع مثل القراعة بعض النص. الإنشاء بترتيب الكلمات في الجمملة. الإملاء بكتابة بعض الجملة. وهلمّ جمَّا.

وقد اتفق علماء التربية و التعليم أن التعليم نظرية واحدة التي تتكون من العوامل ير ابط بعضها ببعض. و من عوامله هي معلم و متعلم (طالب) و مجتمع و دولة و منهج دراسي و غرض التعليم و طريقة و مادة دراسية و تقويم

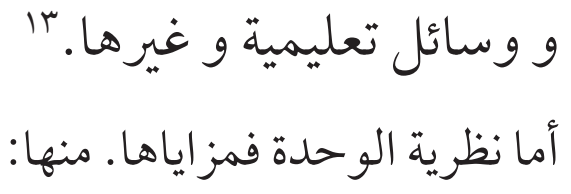

ấL ô

فمن الأسس النفسية أنها تجدد نشاط التلاميذ و تبعث شوقهم وتدفع عنهم السأم و الملل وذلك لتنوع العمل و تلوينه. و أنها تثبت الفهم عن طريق التكرار والرجوع إلى الموضوع الو احد لعلاجه من ختلف النواحي. وانها تنتقل من الكل إلى الجزءء. وهذا يناسب طبيعة

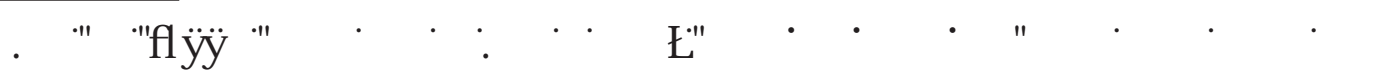

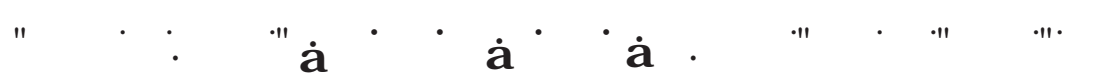

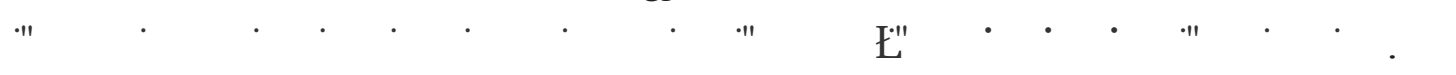




$$
\text { الذه الأسن في إدر اك الأشياء والمعلو مات من الكلّ إلى الجزء. }
$$

من الأسس التربوية أن فيها ربط و ثيق بين ألوان الدراسات اللغوية. حيث يتراوج بيان المعلمّم عن الدراسات اللغوية تصدر من الموضوع الو احد. ويعتبر هذا الشكل فعّاليا للنموّ القدرة اللغوية لدي الطفل.

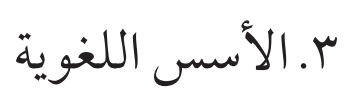

من الأسس اللغوية لهذه الطريقة أنها تناسب الاستعحال الطبيعي للغة لأننا حين نستعمل

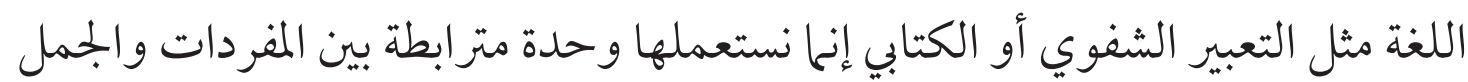

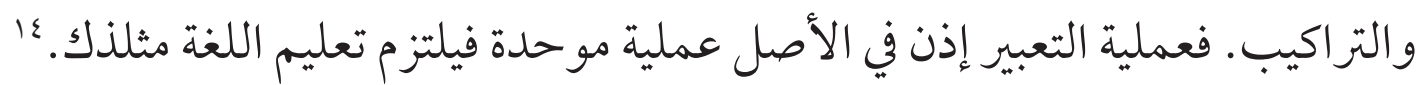

$$
\text { ومن هنا مزايا أخرى هي : }
$$

ا ـ اشتمل هذه النظرية على كل نظرية علوم اللغة الربية عاما.

$$
\text { ץ. المناسب للمبتدئين و المتوسطين. }
$$

r. تيسير التلاميذ لفهم علوم اللغة العربية عاما.

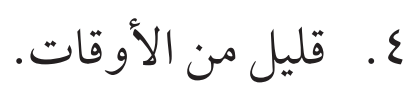

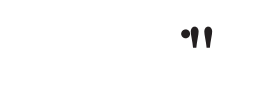

ا. ـ الإنتاج المطور من الكتاب التعليمي لملادة اللغة العربية على أساس نظرية الوحدة له خصائص هي:

• الكتاب المسمى ” الفصحى " لطلبة الصف الأول بمعهد الحكم مالانج • يحتويالكتابالتعليميعلينظريةالو حدةلتدريساللغةالعربيةعلى Y ا وحدةمعدة ولكل وحدة : إستحاع ونطق وقراءة وكتابة اللغة العربية صحيحة وسليمة و

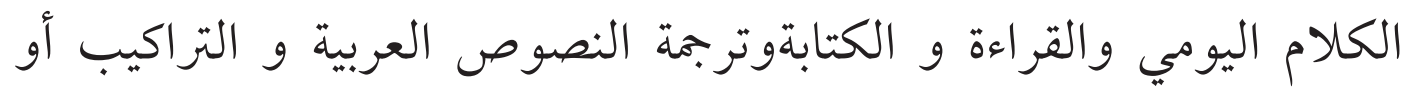




$$
\text { القو اعد وأمثلتها في الآيات القر آنية و المحفوظات }
$$

إن استخدام كتاب التعليمي على أساس نظرية الوحدةلترقية اللغة العربية و كفاءة الطلبة

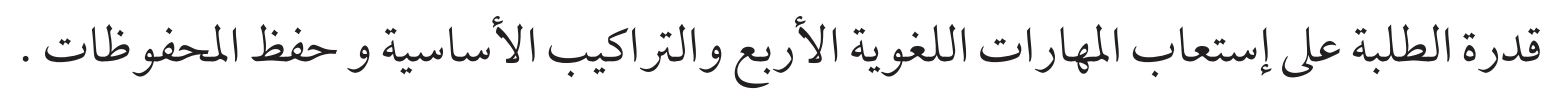

وفهم المنطوق. وفهم المقروء. والتمييز بين الفكرة الرئيسية والجزئية لدى طلبة المعهد الحكمم الماتية

مالانج

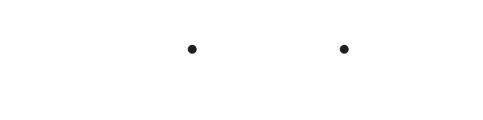

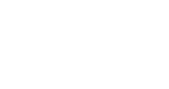

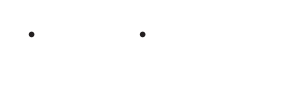

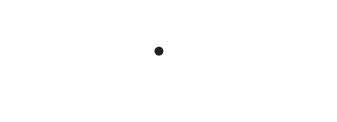

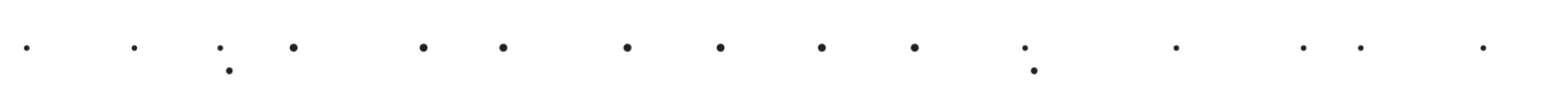

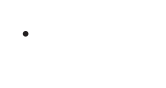

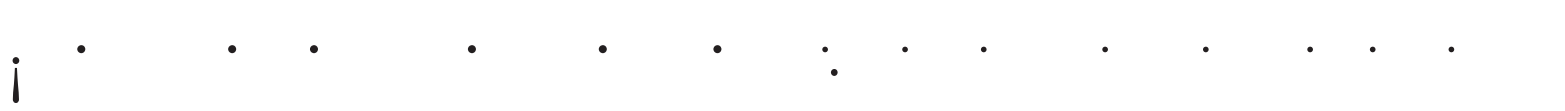
[9 P991四,

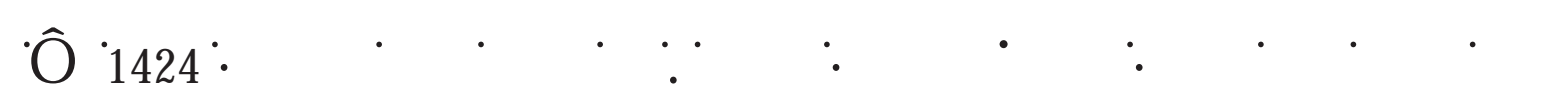

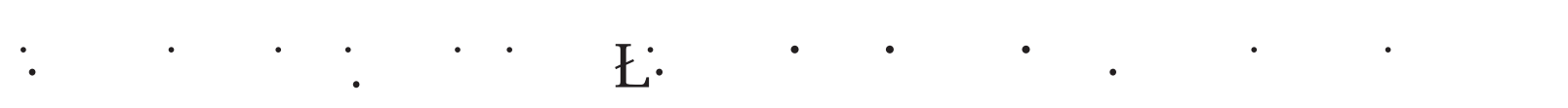
(2002

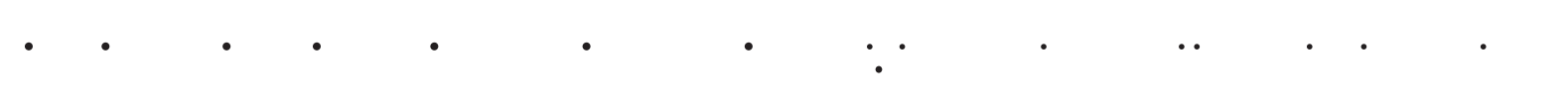

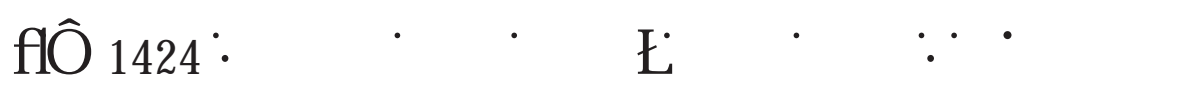

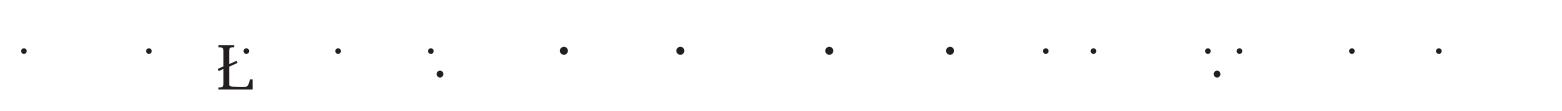

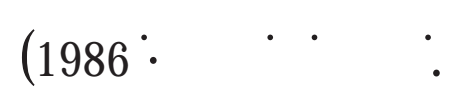




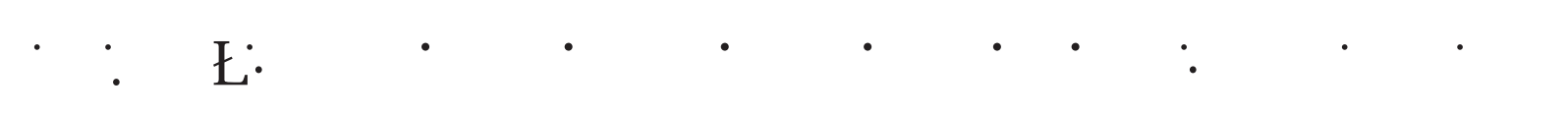

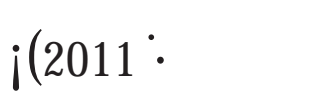

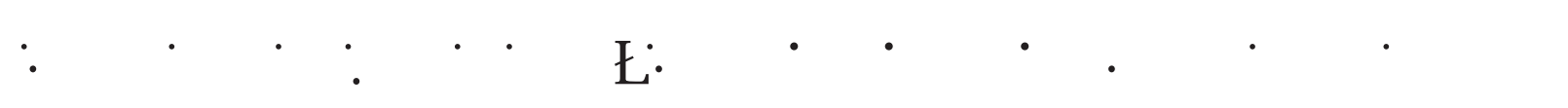
${ }^{9}(2002$

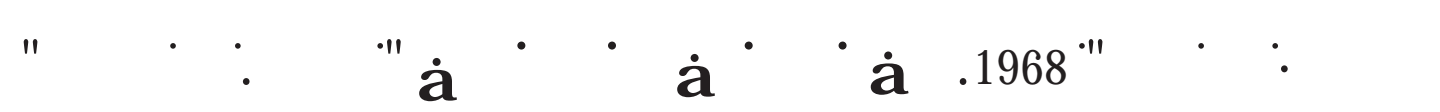

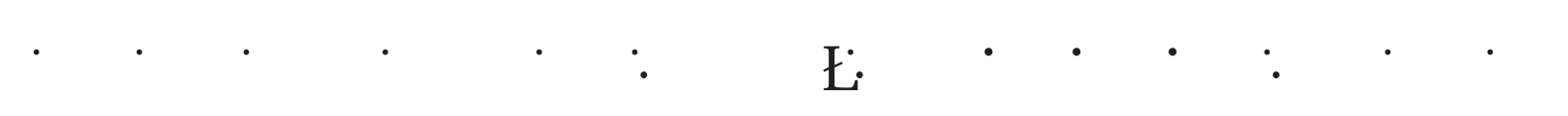

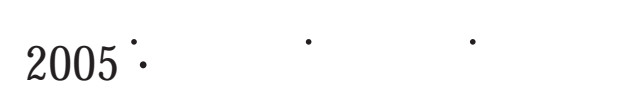

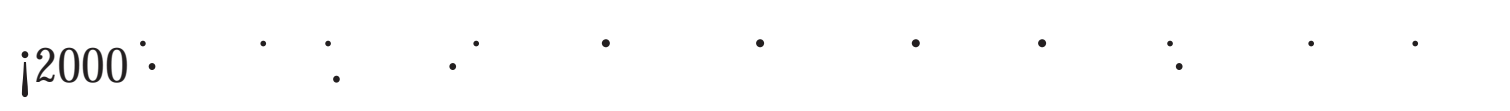

\section{Aderping}

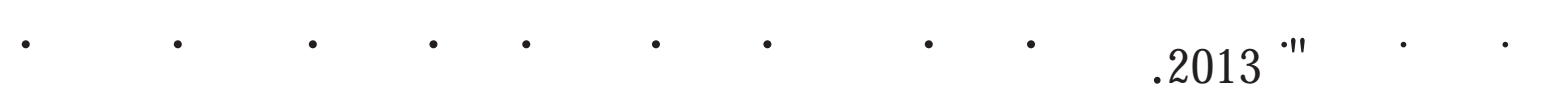

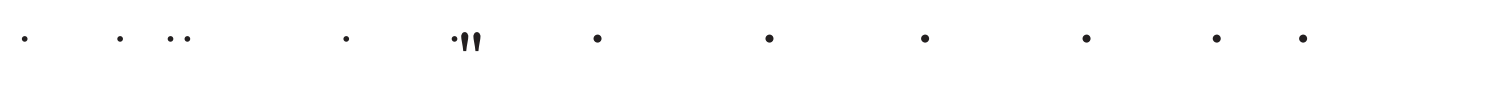

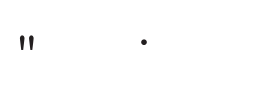

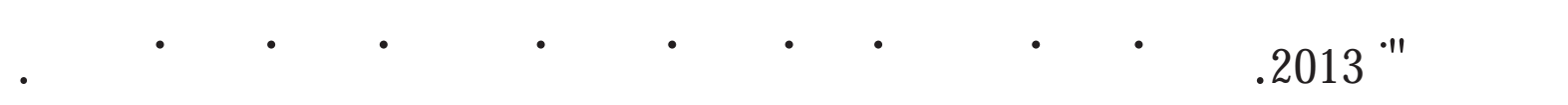

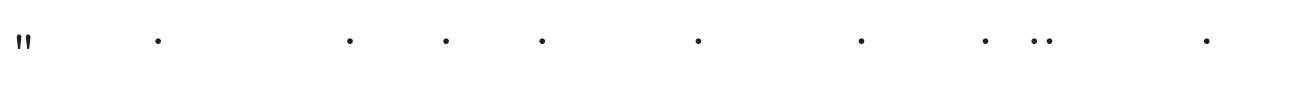

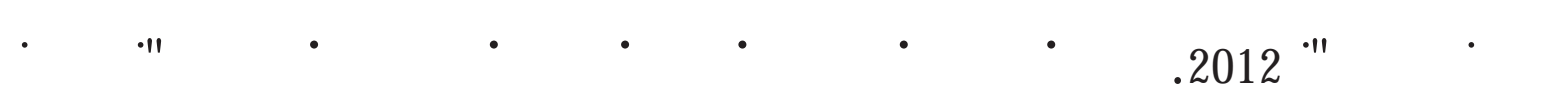

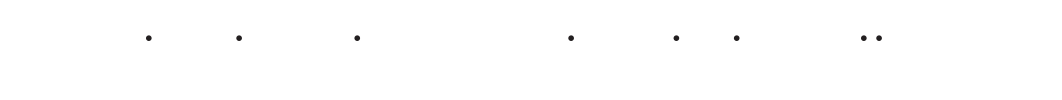

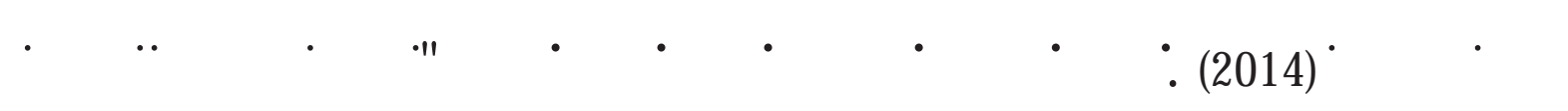

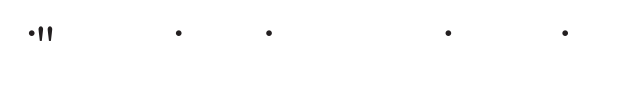




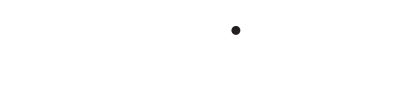

Abdul Hamid, dkk, 2008. PembelajaranBahasa Arab (Pendekatan, Metode, Strategi, Materidan Media. Malang: UIN Press.

Abdullah al-Gali\& Abdul HamidAbdullah.2012. MenyusunBuku Ajar. Padang: AkademiaPermata.

AcepHermawan. 2011. MetodologiPembelajaranBahasa Arab. Bandung: RemajaRosdakarya.

B.P.Sitepu. 2012. PenulisanBukuTeksPelajaran. Bandung: PT. RemajaRosdakarya.

Ekawarna, JurnalMakara, SosialHumanioraUniversitas Indonesia, (Online), 11 (1): 42-47, 2007 "MengembangkanBahan Ajar Mata Kuliah Permodalan Koperasi untuk Meningkatkan Motivasi dan Hasil Belajar Mahasiswa” (http:/ / journal.ui.ac.id/index.php/hu-manities/article/view-File/ 104/ 100),

MohAinin.2013.MetodologiPenelitianBahasa Arab. Malang: Bintang Sejahtera.

Muhammad Nisfiannor.2009. PendekatanStatistika Modern untukIlmuSosial.Jakarta: SalembaHumanika,

PunajiSetyosari.2013. MetodePenelitianPendidikan\& Pengembangan. Jakarta: Prendamedia Group.

Sugiyono. 2013. MetodePenelitianPendidikan. Bandung: Alfabeta, 